\title{
Evaluation of the prognostic value of electrocardiography parameters and heart rhythm in patients with pulmonary hypertension
}

Dirk Bandorski ${ }^{1}$, Harilaos Bogossian ${ }^{2}$, Anja Ecke ${ }^{1}$, Christoph Wiedenroth ${ }^{3}$, Ekkehard Gruenig ${ }^{4}$, Nicola Benjamin ${ }^{4}$, Matthias Arlt ${ }^{5}$, Werner Seeger ${ }^{1}$, Eckhard Mayer ${ }^{3}$, Ardeschir Ghofrani ${ }^{1}$, Reinhard Hoeltgen ${ }^{6 \#}$, Henning Gall ${ }^{1 \#}$

${ }^{1}$ University of Giessen and Marburg Lung Center (UGMLC),

Member of the German Center for Lung Research (DZL), Giessen, Germany

${ }^{2}$ Klinikum Lüdenscheid, Universität Witten-Herdecke, Medizinische Klinik III, Lüdenscheid, Germany

${ }^{3}$ Department of Thoracic Surgery, Kerckhoff Heart and Lung Center, Bad Nauheim, Germany

${ }^{4}$ Center for Pulmonary Hypertension at Thoraxclinic Heidelberg, Heidelberg, Germany

${ }^{5}$ Department of Intensive Care Medicine, Kerckhoff Heart and Lung Center, Bad Nauheim, Germany

${ }^{6}$ Klinikum Westmünsterland, St. Agnes-Hospital Bocholt Rhede,

Medical Clinic 1 - Cardiology/Electrophysiology, Bocholt, Germany

\section{Abstract}

Background: Several studies have analyzed arrhythmias in patients with pulmonary hypertension (PH) and increased P-wave duration was identified as a risk factor for development of atrial fibrillation $(A F)$.

Methods: We retrospectively analyzed the incidence of arrhythmias in patients with an initial diagnosis of PH during long-term follow-up and assessed the prognostic value of electrocardiography (ECG) data. Data from 167 patients were analyzed (Dana Point Classification: Group 1: 59 patients, Group 2: 28 patients, Group 3: 39 patients, Group 4: 41 patients). Clinical, 6-minute walk distance test, echocardiography and right heart catheterization data were collected, and baseline/follow-up ECGs were analyzed.

Results: Baseline ECGs revealed sinus rhythm in 137 patients. Thirteen patients had newly onset AF during follow-up. In 30 patients, baseline ECG showed AF. Patients with baseline $A F$ showed higher atrial diameters and higher right atrial pressure. Patients with $P$-wave $d u$ ration $>0.11$ s had shorter survival. Other ECG parameters (PQ-interval, QRS-width, QT-/ /QTc-interval) were not associated with survival. Mean survival times were $79.4 \pm 5.4$ months (sinus rhythm), $64.4 \pm 12.9$ months (baseline $A F$ ) and $58.8 \pm 8.9$ months (newly onset $A F$ during follow-up) $(p=0.565)$.

Conclusions: Atrial fibrillation predict adverse prognosis in patients with $P H$ and a longer P-wave (>0.11 s) is associated with shorter survival time. (Cardiol J 2016; 23, 4: 465-472)

Key words: pulmonary hypertension, arrhythmia, atrial fibrillation, electrocardiogram

Address for correspondence: Dirk Bandorski, MD, FESC, FACC, University of Giessen and Marburg Lung Center (UGMLC), Member of the German Center for Lung Research (DZL), Klinikstrasse 33, 35392 Giessen, Germany, tel: +49641 98542351, fax: +49641 98542359, e-mail: dirk.bandorski@khw.med.uni-giessen.de

${ }^{\#}$ R. Hoeltgen and H. Gall contributed equally to this article

Received: 11.04.2016 Accepted: 06.06.2016 


\section{Introduction}

Pulmonary hypertension (PH) is defined as an increase of $\geq 25 \mathrm{~mm} \mathrm{Hg}$ in mean pulmonary arterial pressure (mPAP), as well as pulmonary capillary wedge pressure (PCWP) $\leq 15 \mathrm{~mm} \mathrm{Hg}$ or $>15 \mathrm{~mm} \mathrm{Hg}$ in precapillary (Groups 1, 3,4) and postcapillary (Group 2) forms, respectively. The increase in pulmonary vascular resistance leads to an increase in the afterload on the right ventricle, resulting in dilation of the right atrium and ventricle and vascular remodeling [1-4].

Five studies evaluated the incidence of atrial arrhythmias in patients with $\mathrm{PH}$ [5-9]. The cumulative incidence varied between $11.7 \%$ and $25.1 \%$ over periods of $6-13$ years.

Electrophysiological studies have shown that in patients suffering from $\mathrm{PH}$, there is a reduction in regional conduction velocity in the right atrium and an increase in the number of areas with low voltage and electrical silence [10]. A few studies analyzed $\mathrm{P}$-wave duration, which reflects the electrical activation of the atria and its impact on the development of arrhythmias [11-13]. These studies found that $\mathrm{P}$-wave duration is higher in patients developing atrial fibrillation (AF).

This study was performed to elucidate the incidence of arrhythmias during long-term follow-up, the prognostic value of electrocardiogram (ECG) for arrhythmias and the influence of different ECG parameters on survival in patients with newly detected $\mathrm{PH}$.

\section{Methods}

Data of patients with first detection of $\mathrm{PH}$ were analyzed retrospectively. The following data were extracted from patients' medical records: demographic data, etiology of $\mathrm{PH}$, anti-arrhythmic medication, baseline and follow-up ECGs, data from echocardiography and right heart catheterization. The study and the study design were approved by the institutional Review Board (reference number: 106/13). All patients were followed in our outpatient clinic for $\mathrm{PH}$.

\section{Electrocardiogram}

Twelve-lead ECGs with patients in supine position were performed by trained technicians and reviewed by two physicians blinded to the clinical characteristics and outcome of the patients. Commercially available ECG devices (Model Schiller AT-10 plus; Schiller AG, Baar; Switzerland) were used for ECG recordings (paper speed $=50 \mathrm{~mm} / \mathrm{s}$; sensitivity of $10 \mathrm{~mm} / \mathrm{mV}$ ). ECG was recorded from all patients on the first visit (baseline ECG) and at follow-ups in our outpatient clinic. Heart rate and rhythm, P-wave-, PQ-, QRS- and QT(c)-duration and axis of QRS were included in the evaluation. ECG variables were analyzed with standard ECG nomenclature and definitions [14, 15]. For each ECG variable, we defined ranges and analyzed the correlation with mortality.

\section{Echocardiography}

Transthoracic echocardiography was performed using a GE Vivid S 6 (GE, Germany). The following diameters and valves were measured: left atrial diameter (edge-to-edge method, parasternal long axis view), right atrial diameter (4-chamber view, measured at end-systole), right ventricular diameter (4-chamber view, measured at end-diastole), tricuspid annular plane systolic excursion (TAPSE) and systolic pulmonary artery pressure.

All measurements were carried out in accordance with the guidelines of the American Society of Echocardiography [16-20].

\section{Right heart catheterization}

Right heart catheterization was performed via the right jugular vein. Hemodynamic measurements included mean right atrial pressure (mRAP), mPAP, PCWP, pulmonary vascular resistance (PVR), systemic vascular resistance, cardiac index (thermodilution) and venous saturation (ven $\mathrm{sO}_{2}$ ).

\section{Statistical analysis}

Statistical calculations were performed using SPSS (ver. 21; IBM, Armonk, NY). Patient data are presented as absolute numbers (mean or median) and standard deviation (SD) or interquartile range (IQR). Comparisons between groups were made using the t-test or $\chi^{2}$ test, as appropriate. P-values of $<0.05$ were considered statistically significant.

The endpoint was all-cause mortality. Cox regression analyses were performed to evaluate the influence of P-wave-, PQ-, QRS- and QT(c)-duration on survival. Multivariate Cox regression was used to adjust for possible confounders, i.e. age, gender, 6-minute walk distance, and PVR. These parameters were assessed with hazard ratios (HR) of single and multivariate Cox proportional hazards analyses and are given as point estimates and $95 \%$ confidence intervals $(\mathrm{CI})$.

Kaplan-Meier plots were used to illustrate survival in relation to $\mathrm{P}$-wave duration and incidence of cardiac arrhythmias. Statistical analyses were 
performed using data obtained during the entire observation period (up to 10 years), however the presentation of longitudinal survival data covers only 5 years, because the data after this time point were too limited.

\section{Results}

One hundred and sixty-seven patients were included into the analyses. Mean age was $61.5 \pm$ \pm 14.4 years (range 19-84). Patients suffered from various forms of $\mathrm{PH}$ : pulmonary arterial hypertension (Group 1: 59 patients; idiopathic pulmonary arterial hypertension [IPAH], $\mathrm{n}=33$, connective tissue disease [CTD], $\mathrm{n}=19$, congenital heart disease [CHD], $\mathrm{n}=7$ ), $\mathrm{PH}$ associated with left heart disease (pulmonary venous hypertension $[\mathrm{PVH}]$; Group 2: 28 patients), PH associated with lung disease (Group 3: 39 patients; chronic obstructive pulmonary disease [COPD], $\mathrm{n}=16$, interstitial lung disease [ILD], $\mathrm{n}=23$ ) and chronic thromboembolic pulmonary hypertension (CTEPH, Group 4: 41 patients).

When baseline ECGs were recorded, patients were using beta-blockers $(\mathrm{n}=42)$, calcium channel blockers $(n=35)$ or digitalis as antiarrhythmic medication $(\mathrm{n}=13)$, and 17 patients had a cardiac pacemaker which had been fitted to manage bradyarrhythmia (Table 1).

\section{Electrocardiogram}

The mean heart rate was $79 \pm 17 \mathrm{bpm}$ (range: 45-124). The P-wave duration was $0.1 \pm 0.02 \mathrm{~s}$, and the PQ-interval was $0.17 \pm 0.03 \mathrm{~s}$. Mean QRS-width was $0.1 \pm 0.02 \mathrm{~s}$, the QT-interval was
Table 1. Baseline characteristics of patients.

\begin{tabular}{ll} 
All patients & $\mathrm{n}=167$ \\
Gender (female/ & $\mathrm{n}=89(53.3 \%) /$ \\
/male) & $\mathrm{n}=78(46.7 \%)$ \\
Age [years] & $61.5 \pm 14.4$ \\
Medication & BB: $\mathrm{n}=42(25.1 \%)$ \\
& CCB: $\mathrm{n}=35(21.0 \%)$ \\
& BB and CCB: $\mathrm{n}=7(4.3 \%)$ \\
& Digitoxin/Digoxin: $\mathrm{n}=13(7.8 \%)$ \\
\hline
\end{tabular}

$\mathrm{BB}$ - beta-blocker; $\mathrm{CCB}$ - calcium channel blocker

$0.38 \pm 0.05 \mathrm{~s}$ (range: $0.20-0.53$ ) and corrected QT interval $(\mathrm{QTc})=0.41 \pm 0.04 \mathrm{~s}$. Baseline ECGs revealed sinus rhythm (SR) in $137(82 \%)$ patients and $\mathrm{AF}$ in 30 (18\%, age $68.9 \pm 9.8$ years) patients. During follow-up, ECGs revealed SR in 124 (age $58.6 \pm 16.3$ years) patients and newly onset $\mathrm{AF}$ in 13 (7.8\%; age $68.3 \pm 11.2$ years) patients. The $\mathrm{P}$-waves in these patients were normal before onset of AF. In the baseline ECG, AF was most common in patients in $\mathrm{PH}$ Group 2 (16/28 patients, Table 2). Thirty-eight (88.4\%) patients with $\mathrm{AF}$ (in baseline ECG or newly onset during follow-up) were treated with anticoagulants.

$\mathrm{P}$-wave duration was $0.11 \pm 0.02 \mathrm{~s}$ (median: $0.11 \mathrm{~s}$ ) in patients with SR in the baseline ECG and at follow-up, whereas patients with SR in the baseline ECG and AF at follow-up presented a P-wave duration of $0.10 \pm 0.02 \mathrm{~s}$ (median: $0.10 \mathrm{~s}$ ); there was no difference in $\mathrm{P}$-wave duration related to ECG at follow-up ( $\mathrm{p}=0.193)$. The morphology of the P-wave was normal in 111 (66.5\%) patients.

Table 2. Pulmonary hypertension (PH) subgroups and heart rhythm.

\begin{tabular}{|c|c|c|c|c|}
\hline \multirow[t]{2}{*}{ PH-Group } & \multirow[t]{2}{*}{ PH-Subgroup } & \multicolumn{3}{|c|}{ Arrhythmias (n/\%) } \\
\hline & & $\begin{array}{c}\text { Sinus rhythm (baseline } \\
\text { ECG + follow-up, } \\
n=124 \text { ) }\end{array}$ & $\begin{array}{l}\text { AF (baseline ECG, } \\
n=30)\end{array}$ & $\begin{array}{l}\text { AF during follow-up } \\
\qquad(n=13)\end{array}$ \\
\hline \multirow[t]{3}{*}{1} & IPAH $(n=33)$ & $27(81.8 \%)$ & $4(12.1 \%)$ & $2(6.1 \%)$ \\
\hline & CTD $(n=19)$ & $14(73.6 \%)$ & $1(5.3 \%)$ & $4(21.1 \%)$ \\
\hline & $\mathrm{CHD}(\mathrm{n}=7)$ & $5(71.4 \%)$ & $1(14.3 \%)$ & $1(14.3 \%)$ \\
\hline 2 & $\mathrm{PVH}(\mathrm{n}=28)$ & $11(39.3 \%)$ & $16(57.1 \%)$ & $1(3.6 \%)$ \\
\hline \multirow[t]{2}{*}{3} & ILD (n = 23) & $18(78.3 \%)$ & $4(17.4 \%)$ & $1(4.3 \%)$ \\
\hline & $\operatorname{COPD}(n=16)$ & $14(87.5 \%)$ & $0(0 \%)$ & $2(12.5 \%)$ \\
\hline 4 & СТЕРH $(n=41)$ & $35(85.4 \%)$ & $4(9.8 \%)$ & $2(4.8 \%)$ \\
\hline
\end{tabular}

ECG - electrocardiogram; AF — atrial fibrillation; IPAH - idiopathic pulmonary arterial hypertension; CTD - connective tissue disease; CHD - congenital heart disease; PVH — pulmonary venous hypertension; ILD — interstitial lung disease; COPD — chronic obstructive pulmonary disease; CTEPH — chronic thromboembolic pulmonary hypertension
pul 
Table 3. Pulmonary hypertension (PH) subgroups and electrocardiography-parameters.

\begin{tabular}{lccccc}
\hline PH-Group & $\begin{array}{c}\text { P-wave } \\
\text { duration }[\mathbf{s}]\end{array}$ & $\begin{array}{c}\text { PQ-interval } \\
{[\mathbf{s}]}\end{array}$ & $\begin{array}{c}\text { QRS-width } \\
{[\mathbf{s}]}\end{array}$ & $\begin{array}{c}\text { QT-interval } \\
{[\mathbf{s}]}\end{array}$ & $\begin{array}{c}\text { QTc-interval } \\
{[\mathbf{s}]}\end{array}$ \\
\hline $\begin{array}{l}\text { Idiopathic pulmonary arterial } \\
\text { hypertension }\end{array}$ & $0.10 \pm 0.0 .2$ & $0.18 \pm 0.03$ & $0.10 \pm 0.02$ & $0.39 \pm 0.04$ & $0.42 \pm 0.03$ \\
Connective tissue disease & $0.10 \pm 0.01$ & $0.16 \pm 0.02$ & $0.09 \pm 0.02$ & $0.38 \pm 0.06$ & $0.42 \pm 0.05$ \\
Congenital heart disease & $0.10 \pm 0.01$ & $0.17 \pm 0.01$ & $0.10 \pm 0.02$ & $0.42 \pm 0.07$ & $0.42 \pm 0.06$ \\
Pulmonary venous hypertension & $0.12 \pm 0.03$ & $0.16 \pm 0.03$ & $0.09 \pm 0.01$ & $0.39 \pm 0.02$ & $0.43 \pm 0.04$ \\
Interstitial lung disease & $0.11 \pm 0.01$ & $0.17 \pm 0.02$ & $0.09 \pm 0.02$ & $0.37 \pm 0.03$ & $0.41 \pm 0.03$ \\
$\begin{array}{l}\text { Chronic obstructive } \\
\text { pulmonary disease }\end{array}$ & $0.10 \pm 0.01$ & $0.16 \pm 0.03$ & $0.10 \pm 0.02$ & $0.35 \pm 0.04$ & $0.39 \pm 0.03$ \\
Chronic thromboembolic PH & $0.11 \pm 0.02$ & $0.17 \pm 0.03$ & $0.10 \pm 0.02$ & $0.38 \pm 0.04$ & $0.41 \pm 0.03$ \\
\hline
\end{tabular}

In $26(15.5 \%)$ patients, ECG revealed an increased amplitude of the $\mathrm{P}$-wave.

The most common axis types were normal ( $\mathrm{n}=105 ; 62.8 \%)$. Right axis deviation was found in $39(23.4 \%)$ patients and left axis deviation in $23(13.8 \%)$ patients.

Extrasystoles (ES) were rare, the baseline ECG revealed supraventricular ES in $11(4.7 \%)$ patients and ventricular ES in 13 patients (range 1-3/ECG).

Subgroup analysis of the ECG parameters did not reveal clinically relevant differences. Statistical significance was found for the following ECG parameters: P-wave duration: IPAH vs. PVH ( $\mathrm{p}=$ $=0.004)$, CTD vs. PVH ( $p=0.007)$, CHD vs. PVH $(\mathrm{p}=0.032)$, COPD vs. PVH $(\mathrm{p}=0.026)$, IPAH vs. ILD ( $p=0.02)$, CTD vs. ILD ( $=0.029)$; PQ-interval: IPAH vs. CTD ( $p=0.037)$, QRS-width: CTD vs. CTEPH ( $p=0.032)$, QT-interval: IPAH vs. ILD $(\mathrm{p}=0.009)$, IPAH vs. COPD $(\mathrm{p}=0.001)$, CTD vs. PVH ( $p=0.039)$, ILD vs. PVH $(p=0.001)$, COPD vs. PVH ( $p<0.001)$, CTEPH vs. PVH $(\mathrm{p}=0.047)$, CHD vs. COPD $(\mathrm{p}=0.011)$ and QTc-interval: IPAH vs. COPD ( $\mathrm{p}=0.007)$ (Table 3$)$.

\section{Six-minute walk test}

One hundred and thirty-two patients underwent a 6 -minute walk test; the remaining patients were unable to walk owing to their clinical state. Patients walked $303 \pm 120 \mathrm{~m}$ in $6 \mathrm{~min}$. The mean walking distance was $305 \pm 124 \mathrm{~m}$ for patients with SR in the baseline ECG, $284 \pm 112 \mathrm{~m}$ for patients with newly onset AF during follow-up, and $305 \pm$ $\pm 108 \mathrm{~m}$ for patients with AF in the baseline ECG. The differences were without statistical significance $(\mathrm{p}=0.881)$.
Hemodynamic parameters evaluated by echocardiography and right heart catheterization

Cardiac function and hemodynamic parameters were evaluated with echocardiography and right heart catheterization. The diameters of the right and left atria were elevated in patients with AF in baseline ECG (baseline SR vs. baseline AF: right atrium: $p=0.279$, left atrium: $p<0.0001$; baseline AF vs. newly onset AF during follow-up: right atrium: $\mathrm{p}=0.175$, left atrium: $\mathrm{p}=0.008$ ). Right heart catheterization revealed highest RAP in patients with baseline AF (baseline SR vs. baseline AF: $p=0.288$; baseline AF vs. newly onset $\mathrm{AF}$ during follow-up: $\mathrm{p}=0.549$; follow-up SR vs. $\mathrm{AF}$ during follow-up: $\mathrm{p}=0.044$ ) (Table 4 ).

\section{Mortality $(\mathrm{n}=148)$}

Survival data were available for 148 patients (113 patients SR during follow-up, 9 patients with newly onset $\mathrm{AF}$ during follow-up, 26 patients with $\mathrm{AF}$ in baseline ECG). ECG parameters (P-waveduration, $\mathrm{PQ}$-interval, QRS-width, QTc-interval) were divided into range categories (Tables 5,6 ) for analysis of survival. SR in the baseline ECG (and therefore possibility for interpretation of $\mathrm{P}$-wave duration and $\mathrm{PQ}$-interval) was recorded in $122 \mathrm{pa}-$ tients. QRS-width and QT-/QTc-intervals were analyzed in all patients $(\mathrm{n}=148)$.

\section{Mortality and ECG parameters}

Patients with short P-waves $(<0.1 \mathrm{~s})$ showed improved survival rates compared to patients with long P-waves (>0.11 s) (Table 5). Univariate Cox regression analysis showed a significant associa- 
Table 4. Echocardiography and right heart catheterization data.

\begin{tabular}{|c|c|c|c|}
\hline Parameter & $\begin{array}{c}\text { Sinus rhythm } \\
\text { (baseline ECG, } \\
n=124 \text { ) }\end{array}$ & $\begin{array}{c}\text { AF (baseline ECG, } \\
n=30)\end{array}$ & $\begin{array}{l}\text { AF during } \\
\text { follow-up } \\
(\mathrm{n}=13)\end{array}$ \\
\hline \multicolumn{4}{|l|}{ Echocardiography } \\
\hline Right atrium diameter [mm] & $53 \pm 10$ & $58 \pm 12$ & $51 \pm 7$ \\
\hline Left atrium diameter $[\mathrm{mm}]$ & $38 \pm 7$ & $46 \pm 5$ & $38 \pm 7$ \\
\hline Right ventricle diameter [mm] & $42 \pm 8$ & $46 \pm 11$ & $50 \pm 12$ \\
\hline TAPSE $[\mathrm{mm}]$ & $18 \pm 5$ & $15 \pm 5$ & $19 \pm 4$ \\
\hline Systolic pulmonary arterial pressure $[\mathrm{mm} \mathrm{Hg}]$ & $63 \pm 25$ & $64 \pm 17$ & $64 \pm 26$ \\
\hline \multicolumn{4}{|l|}{ Right heart catheterization } \\
\hline Mean pulmonary arterial pressure $[\mathrm{mm} \mathrm{Hg}]$ & $43 \pm 15$ & $40 \pm 9$ & $39 \pm 13$ \\
\hline Right atrial pressure $[\mathrm{mm} \mathrm{Hg}]$ & $7 \pm 5$ & $10 \pm 6$ & $5 \pm 4$ \\
\hline Cardiac index $\left[\mathrm{L} / \mathrm{min} / \mathrm{m}^{2}\right]$ & $2.4 \pm 0.6$ & $2.4 \pm 0.8$ & $2.6 \pm 0.7$ \\
\hline Cardiac output [L/min] & $4.5 \pm 1.2$ & $4.7 \pm 1.7$ & $4.6 \pm 1.1$ \\
\hline venous oxygen saturation [\%] & $65 \pm 8 \%$ & $64 \pm 7$ & $64 \pm 6$ \\
\hline Pulmonary vascular resistance $\left[\mathrm{dyn} \times \mathrm{s} \times \mathrm{cm}^{-5}\right]$ & 526 [IOR 615] & 442 [IOR 259] & 569 [IOR 364] \\
\hline
\end{tabular}

ECG - electrocardiogram; AF — atrial fibrillation; TAPSE — tricuspid annular plane systolic excursion; IQR — interquartile range

Table 5. P-wave duration and survival.

\begin{tabular}{lccccc}
\hline P-wave-duration [s] & \multicolumn{3}{c}{ Estimated survival rate [as \%] } & \multirow{2}{*}{$\begin{array}{c}\text { Mean survival } \\
\text { [months] }\end{array}$} & Deaths [n] \\
\cline { 2 - 4 } & $\mathbf{1}$ year & 3 years & $\mathbf{5}$ years & & \\
\hline$<0.1(n=60)$ & 89.7 & 81.0 & 70.2 & $88.1 \pm 6.7$ & 24 \\
$0.1-0.11(n=24)$ & 81.8 & 67.4 & 61.8 & $62 \pm 9.4$ & 9 \\
$>0.11(n=38)$ & 77.4 & 55.8 & 42.1 & $49 \pm 5.8$ & 19 \\
\hline
\end{tabular}

Table 6. Electrocardiography (ECG) parameters and survival.

\begin{tabular}{|c|c|c|c|c|c|}
\hline \multirow[t]{2}{*}{ ECG-parameter [s] } & \multicolumn{3}{|c|}{ Estimated survival rate [as \%] } & \multirow{2}{*}{$\begin{array}{l}\text { Mean survival } \\
\text { [months] }\end{array}$} & \multirow[t]{2}{*}{ Deaths [n] } \\
\hline & 1 year & 3 years & 5 years & & \\
\hline$P Q<0.16(n=65)$ & 85.4 & 68.5 & 63.0 & $80.5 \pm 7.1$ & 27 \\
\hline PQ 0.16-0.17 (n= 16) & 75.0 & 62.5 & 37.5 & $50.5 \pm 10.4$ & 10 \\
\hline$P Q>0.17(n=41)$ & 92.1 & 84.0 & 65.7 & $78.9 \pm 7.5$ & 15 \\
\hline QRS $<0.09(n=64)$ & 87.7 & 70.7 & 57.4 & $78.2 \pm 7.6$ & 25 \\
\hline QRS $0.09-0.1(n=39)$ & 81.1 & 69.9 & 58.5 & $67.3 \pm 7.5$ & 18 \\
\hline QRS $>0.1(n=45)$ & 80.8 & 65.9 & 57.7 & $75.7 \pm 8.5$ & 19 \\
\hline QT < $0.36(n=57)$ & 81.5 & 68.5 & 58.3 & $74.4 \pm 7.5$ & 27 \\
\hline QT $0.36-0.4(n=46)$ & 90.4 & 72.8 & 61.3 & $79.8 \pm 7.4$ & 16 \\
\hline $\mathrm{QT}>0.4(\mathrm{n}=45)$ & 77.6 & 60.5 & 53.7 & $70.4 \pm 8.9$ & 19 \\
\hline QTc $<0.40(n=51)$ & 84.9 & 71.1 & 55.9 & $73.1 \pm 8.0$ & 22 \\
\hline QTc $0.40-0.43(n=42)$ & 82.1 & 71.1 & 51.3 & $64.9 \pm 8.5$ & 23 \\
\hline OTc $>0.43(n=55)$ & 84.3 & 73.5 & 65.8 & $88.7 \pm 7.7$ & 17 \\
\hline
\end{tabular}




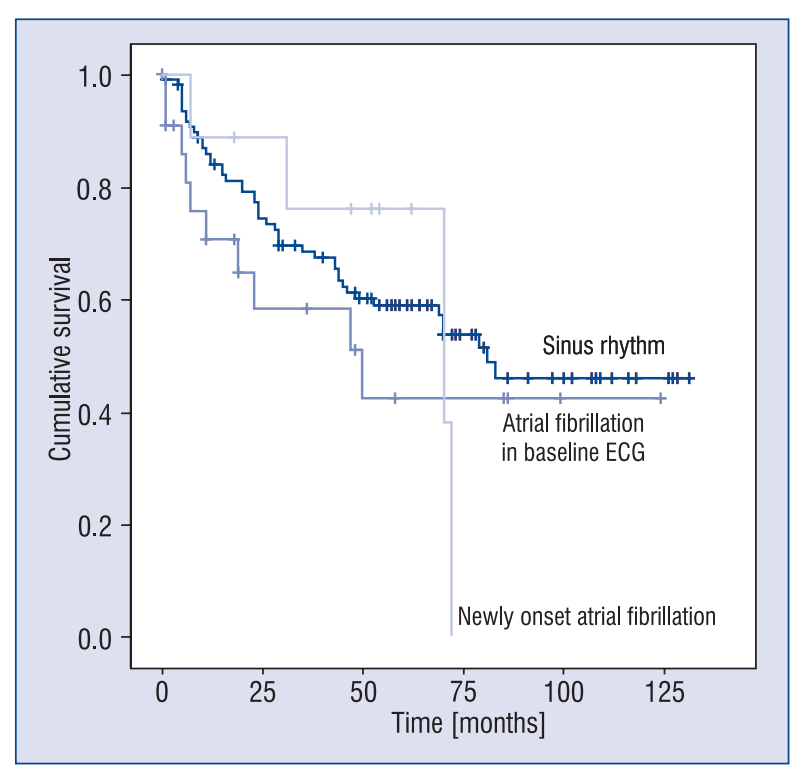

Figure 1. Heart rhythm and survival.

tion between duration of the P-wave and survival $(\mathrm{HR}=2.04,95 \%$ CI: $1.10-3.79, \mathrm{p}=0.024)$ (duration $<0.1 \mathrm{~s}$ vs. $>0.11 \mathrm{~s})$. In a multivariate analysis, this association was borderline significant $(p=0.060)$ when age was included as a covariate (SR at baseline and follow-up: age $61 \pm 15$ years; SR at baseline and $\mathrm{AF}$ at follow-up, age $68 \pm 11$ years; $\mathrm{AF}$ at baseline: age $70 \pm 8$ years). None of the other ECG parameters were associated with survival.

Data relating the other ECG parameters $(\mathrm{PQ}$; QRS; QT; QTc) to survival are shown in Table 6. There was no correlation between duration of the intervals and survival (PQ: $\mathrm{p}=0.121$; $\mathrm{QRS}$ : $\mathrm{p}=0.984$; QT: $\mathrm{p}=0.482$; QTc: $\mathrm{p}=0.128$ ).

\section{Mortality and heart rhythm}

Electrocardiogram of analyzed patients showed SR during follow-up in 113 patients, AF in the baseline ECG in 26 patients and newly onset AF during follow-up in 9 patients. Forty-two percent of the patients $(n=62)$ died during follow-up. Their basic rhythm situation was distributed as follows: 48 showed SR during follow-up, 10 patients had AF in the baseline ECG, and 4 showed newly onset AF during follow-up. Mean survival from diagnosis was $79.4 \pm 5.4$ months vs. $64.4 \pm 12.9$ months vs. $58.8 \pm$ \pm 8.9 months; $\mathrm{p}=0.565$ ).

Multivariate analysis revealed that age confounded the association between onset or prevalence of arrhythmias and survival (Fig. 1).

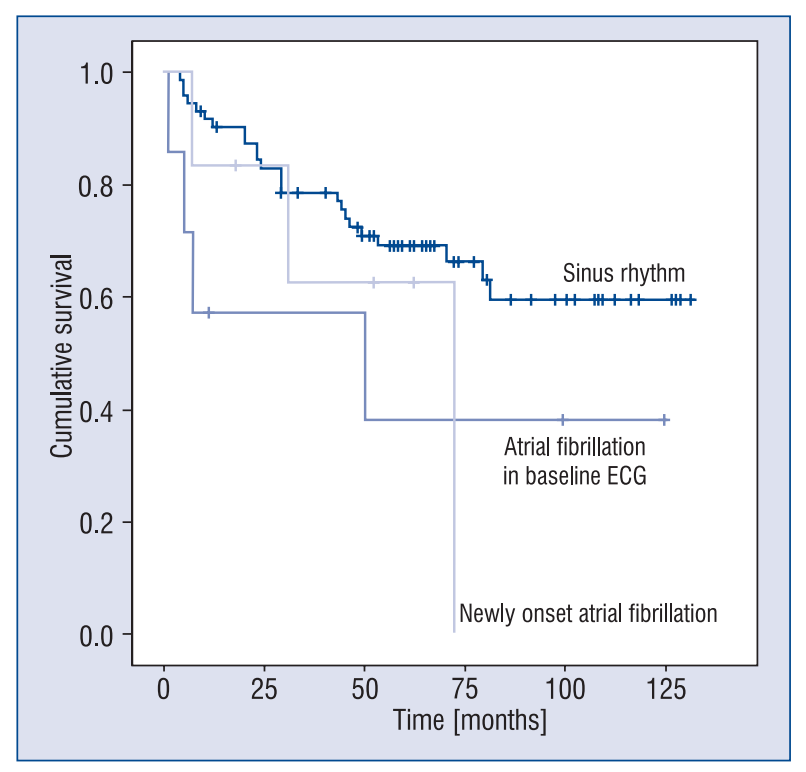

Figure 2. Heart rhythm and survival (patients of pulmonary hypertension Group 1 and Group 4).

To match our results with other studies $[5,6$, 9] we investigated survival in patients $(\mathrm{n}=100)$ of PH Groups 1 and 4. Survival data were available for 84 patients and 31 (37\%) of them died during follow-up. Survival was distributed as follows: patients with SR $93.3 \pm 6.2$ months, patients with $\mathrm{AF}$ in baseline ECG $58.6 \pm 21.2$ months and patients with newly onset AF during follow-up $52.6 \pm 13.6$ months $(\mathrm{p}=0.151)$.

Correspondent to the analysis of all patients $(n=148)$, multivariate analysis revealed age as a confounder for the association between onset or prevalence of arrhythmias and survival (Fig. 2).

\section{Discussion}

The incidence and prognostic relevance of arrhythmias during follow-up in patients with $\mathrm{PH}$ has been evaluated in three studies [5, 6, 9]. Similar to these studies, we found only supraventricular arrhythmias in this patient population, however only $7.8 \%$ of our patients developed AF during follow-up (Tongers: 11.7\%; Olsson: 20.8\%; Wen: $14.3 \%)$. This finding is noteworthy due to the fact that our patients were older than those in the other studies cited (mean age: Olsson: 55 years; Tongers: 48 years; Wen: 39 years) $[5,6,9]$ and it is well-known that the prevalence of AF increases with age, from $0.5 \%$ at $40-50$ years, to $5-15 \%$ at 80 years [20]. Nevertheless, our subgroup analysis 
revealed that patients with AF in the baseline ECG or during follow-up were older than patients with SR (AF in baseline ECG: $70 \pm 8.5$ years, newly onset AF during follow up: $68 \pm 11$ years and SR during follow-up: $61 \pm 15$ years, respectively; baseline AF vs. SR: $p=0.002$, newly onset $A F$ during follow-up vs. SR: $p=0.110$ ), however there was no age difference between patients who had $\mathrm{AF}$ at baseline and those who developed AF during follow-up $(p=0.705)$. Mean survival time was shorter in patients with AF but this effect was not statistically significant.

Rottlaender's et al. study [8] revealed reduced TAPSE in patients with evidence of AF. These results are consistent with our study, which found reduced TAPSE in patients with $\mathrm{AF}$ in baseline ECG $(15 \pm 5 \mathrm{~mm})$ compared with those with SR in the baseline ECG $(18 \pm 5 \mathrm{~mm})$. Patients who developed AF during follow-up had similar TAPSE to patients with SR. Taking into consideration the study of Forfia et al. [21] which analyzed prognostic relevance of TAPSE in patients with $\mathrm{PE}$, reduction of TAPSE in our patients could be an explanation of shorter survival in patients with AF in baseline ECG (and reduced TAPSE).

The same as Wen et al. [9] we found that right ventricular diameter was the only parameter that was elevated in patients with $\mathrm{AF}$ at baseline and during follow-up $(\mathrm{p}=0.222)$. Further parameters known to be increased in patients with $\mathrm{PH}$ and arrhythmias are RAP and PVR [5, 8, 9]. Interestingly, in our study, RAP in patients who developed AF during follow-up ( $7 \pm 5$ vs. $5 \pm 4 \mathrm{~mm} \mathrm{Hg}$ ) was lower than in other studies. The increase in PVR was without clinical relevance (follow-up AF: 526 dyn $\times$ $\mathrm{s} \times \mathrm{cm}^{-5}$; SR: 569 dyn $\left.\times \mathrm{s} \times \mathrm{cm}^{-5}\right)$. Interpretation of these results should take into consideration that our data for right heart catheterization are baseline data, and do not permit the detection of a progressive increase in RAP or PVR before onset of AF during follow-up. As in other studies, raised RAP and PVR seem to be risk factors for arrhythmias in patients with $\mathrm{PH}$.

The prognostic value of various ECG parameters has been analyzed in multiple studies. In a study which was controlled for variance in age and gender, increased P-wave duration was identified as a risk factor for development of AF $[12,13]$. Genovesi et al. [11] investigated P-wave duration in hemodialysis patients with and without $\mathrm{AF}$ and reported that $\mathrm{P}$-wave duration was longer (153 $\pm 16 \mathrm{~ms}$ ) in patients with a history of AF than in patients without AF. These results are not directly comparable with ours, as unlike our sample many of their patients suffered from reduced left ventricular function and left ventricular hypertrophy. We found no difference in $\mathrm{P}$-wave duration between patients with and without AF during follow-up. Sun et al. [22] analyzed QRS width in the initial 12-lead ECG in 212 patients with idiopathic $\mathrm{PH}$; an increase $\geq 0.12 \mathrm{~s}$, which was observed in $16.5 \%$ of patients, was shown to be an independent predictor of mortality; it was associated with a 2.5 times greater risk of death. In their study, QRS prolongation was positively correlated with right atrium and right ventricle diameters suggesting that right ventricular overload may play a role in the pathogenesis of $\mathrm{PH}$. Hemodynamic variables were similar in the two groups (Group 1: QRS < $120 \mathrm{~ms}$ and Group 2: QRS $\geq 120 \mathrm{~ms}$ ): mRAP (Group 1: $7.4 \pm 5.9 \mathrm{~mm} \mathrm{Hg}$; Group 2: $8.6 \pm 7.8 \mathrm{~mm} \mathrm{Hg}$; $=0.30$ ), mPAP (Group 1: $61.1 \pm 16.1 \mathrm{~mm} \mathrm{Hg}$, Group 2: $60.9 \pm 18.7 \mathrm{~mm} \mathrm{Hg}$; $\mathrm{p}=0.53$ ) and PVR (Group 1: $17 \pm 10.3$ Wood units, Group 2: $18.5 \pm 9.8$ Wood units; $\mathrm{p}=0.69$ ). In our study, patients in the longest QRS duration category $(>0.1 \mathrm{~s})$ survival times were not shorter than for other patients, although atrial diameter and PVR were lower.

There have been two studies comparing duration of the QTc-interval in controls and patients with different types of PH [23, 24]. The QTc interval was longer in patients with $\mathrm{PH}$ than in controls (Hong-Liang's study, severe PH: $428.6 \pm 32.8 \mathrm{~ms}$, mild to moderate $\mathrm{PH}: 423.1 \pm 30.2 \mathrm{~ms}$; controls: $411.1 \pm 28.4 \mathrm{~ms}$; criteria for mild to moderate $\mathrm{PH}$ : $\mathrm{mPAP} \geq 25 \mathrm{~mm} \mathrm{Hg}$ and $<60 \mathrm{~mm} \mathrm{Hg}$, criteria for severe PH: $\mathrm{mPAP} \geq 60 \mathrm{~mm} \mathrm{Hg}$ ) [23]. In Rich's et al. study [24], the QTc interval was $454.8 \pm 29 \mathrm{~ms}$ in patients with $\mathrm{PH}$ compared with $429 \pm 18 \mathrm{~ms}$ in controls. The mPAP of our patients was lower than in the comparable group in Hong-Liang's study (patients with mild-to-moderate $\mathrm{PH}$ ) and lower than in Rich's study. Rich's sample clearly had higher pulmonary vascular resistance than our sample, and Hong-Liang did not provide these data [23, 24]. The shorter QTc interval in our patients may have been due to lower dilatation of the right ventricle. Hong-Liang did not give echocardiographic data and only approximately $10 \%$ of the $\mathrm{PH}$ patients $(24 / 202)$ in this study underwent cardiac magnetic resonance imaging, which revealed reduced systolic function and markedly higher mean right ventricular volume and mass.

\section{Limitations of the study}

Our study is not free of limitations. The retrospective design may have led to an underestimation of the incidence of arrhythmias because the 
ECGs were taken periodically and cardiac rhythm was only monitored for a few seconds each time, therefore self-limiting episodes of arrhythmia may have been missed. Echocardiographic and right heart catheterization data were not available for the follow-up period. The study sample contained patients in all $\mathrm{PH}$ groups except Group 5, and compared to other studies Group 2 was over-represented, which makes it difficult to compare our results with the other published studies in which most of the patients were in PH Groups 1 and 4.

\section{Conclusions}

Atrial fibrillation predicts adverse prognosis in patients with $\mathrm{PH}$, and a longer $\mathrm{P}$-wave $(>0.11 \mathrm{~s})$ is associated with shorter survival time. This association is confounded by age and is therefore important for younger patients suffering from pulmonary hypertension.

\section{Conflict of interest: None declared}

\section{References}

1. Archer S, Rich S. Primary pulmonary hypertension: A vascular biology and translational research "Work in progress". Circulation, 2000; 102: 2781-2791.

2. Newman JH, Fanburg BL, Archer SL et al.; National Heart, Lung and Blood Institute/Office of Rare Diseases. Pulmonary arterial hypertension: Future directions: report of a National Heart, Lung and Blood Institute/Office of Rare Diseases workshop. Circulation, 2004; 109: 2947-2952.

3. Runo JR, Loyd JE. Primary pulmonary hypertension. Lancet, 2003; 361: 1533-1544.

4. Humbert M, Morrell NW, Archer SL et al. Cellular and molecular pathobiology of pulmonary arterial hypertension. J Am Coll Cardiol, 2004; 43 (12 suppl. S): 13S-24S.

5. Olsson KM1, Nickel NP, Tongers J, Hoeper MM. Atrial flutter and fibrillation in patients with pulmonary hypertension. Int J Cardiol, 2013; 167: 2300-2305. doi: 10.1016/j.ijcard.2012. 06.024 .

6. Tongers J, Schwerdtfeger B, Klein G et al. Incidence and clinical relevance of supraventricular tachyarrhythmias in pulmonary hypertension. Am Heart J, 2007; 153: 127-132.

7. Ruiz-Cano MJ, Gonzalez-Mansilla A, Escribano P et al. Clinical implications of supraventricular arrhythmias in patients with severe pulmonary arterial hypertension. Int J Cardiol, 2011; 146: 105-106. doi: 10.1016/j.ijcard.2010.09.065.

8. Rottlaender D, Motloch LJ, Schmidt D et al. Clinical impact of atrial fibrillation in patients with pulmonary hypertension. PLoS ONE, 2012; 7: e33902. doi: 10.1371/journal.pone.0033902.

9. Wen L, Sun ML, An P et al. Frequency of supraventricular arrhythmias in patients with idiopathic pulmonary arterial hypertension. Am J Cardiol, 2014; 114: 1420-1425. doi: 10.1016/j. amjcard.2014.07.079.
10. Medi C, Kalman JM, Ling LH et al. Atrial electrical and structural remodeling associated with longstanding pulmonary hypertension and right ventricular hypertrophy in humans. J Cardiovasc Electrophysiol, 2012; 23: 614-620. doi: 10.1111/j.1540-8167.2011.02255.x.

11. Genovesi S, Fabbrini P, Pieruzzi F et al. Atrial fibrillation in end stage renal disease patients: Influence of hemodialysis on $P$ wave duration and atrial dimension. J Nephrol, 2015; 28: 615-621. doi: 10.1007/s40620-014-0131-7.

12. Magnani JW, Johnson VM, Sullivan LM et al. P wave duration and risk of longitudinal atrial fibrillation in persons $\geq 60$ years old (from the Framingham Heart Study). Am J Cardiol, 2011; 107: 917-21.e1. doi: 10.1016/j.amjcard.2010.10.075.

13. Perez MV, Dewey FE, Marcus R et al. Electrocardiographic predictors of atrial fibrillation. Am Heart J, 2009; 158: 622-628. doi: 10.1016/j.ahj.2009.08.002.

14. Goldman M. Principles of clinical electrocardiography. 12th Ed. Lange Medical Publications, Los Altos, CA 1986.

15. Schamroth L. Introduction to electrocardiography. 7th Ed. Blackwell Scientific Publications, London, UK 1990.

16. Rudski LG, Lai WW, Afilalo J et al. Guidelines for the echocardiographic assessment of the right heart in adults: A report from the American Society of Echocardiography endorsed by the European Association of Echocardiography, a registered branch of the European Society of Cardiology, and the Canadian Society of Echocardiography. J Am Soc Echocardiogr, 2010; 23: 685-713. doi: 10.1016/j.echo.2010.05.010.

17. Lang RM, Bierig M, Devereux RB et al. Recommendations for chamber quantification: A report from the American Society of Echocardiography's Guidelines and Standards Committee and the Chamber Quantification Writing Group, Developed in conjunction with the European Association of Echocardiography, a branch of the European Society of Cardiology. J Am Soc Echocardiogr, 2005; 18: 1440-1463.

18. Baumgartner H, Hung J, Bermejo J et al. Echocardiographic assessment of valve stenosis: EAE/ASE recommendations for clinical practice. Eur J Echocardiogr, 2009; 10: 1-25. doi: 10.1093/ ejechocard/jen303.

19. Zoghbi WA, Enriquez-Sarano M, Foster E et al. Recommendations for evaluation of the severity of native valvular regurgitation with two-dimensional and Doppler echocardiography. J Am Soc Echocardiogr, 2003; 16: 777-802.

20. Camm AJ, Kirchhof P, Lip GY et al. Guidelines for the management of atrial fibrillation: The Task Force for the Management of Atrial Fibrillation of the European Society of Cardiology (ESC). Eur Heart J, 2010; 31: 2369-2429. doi: 10.1093/eurheartj/ehq278.

21. Forfia PR, Fisher MR, Mathai SC et al. Tricuspid annular displacement predicts survival in pulmonary hypertension. Am J Respir Crit Care Med, 2006; 174: 1034-1041.

22. Sun PY, Jiang X, Gomberg-Maitland M et al. Prolonged QRS duration: A new predictor of adverse outcome in idiopathic pulmonary arterial hypertension. Chest, 2012; 141: 374-380. doi: 10.1378/chest.10-3331.

23. Hong-liang Z, Qin L, Zhi-hong L et al. Heart rate-corrected QT interval and QT dispersion in patients with pulmonary hypertension. Wien Klin Wochenschr, 2009; 121: 330-333. doi: 10.1007/ s00508-009-1184-9.

24. Rich JD, Thenappan T, Freed B et al. QTc prolongation is associated with impaired right ventricular function and predicts mortality in pulmonary hypertension. Int J Cardiol, 2013; 167: 669-676. doi: 10.1016/j.ijcard.2012.03.071. 